\title{
AGILITY IN INFORMATION SYSTEMS DEVELOPMENT: A Three-Tiered Framework
}

\author{
Kieran Conboy \\ National University of Ireland \\ Galway, Ireland \\ Brian Fitzgerald \\ University of Limerick \\ Limerick, lreland \\ William Golden \\ National University of Iretand \\ Galway, Ireland
}

\begin{abstract}
The Agile Manifesto was put forward in 2001, and several method instantiations, such as XP, SCRUM and Crystal exist. Each atheres to some principles of the Agile Manifesto and disregards others. This paper proposes that these Agile Manifesto principles are insufficiently grounded in theory, and are largely naive to the concept of agility outside the field of software development. This research aims to develop a broad, three-tiered framework of ISD agility based on a thorough review of agility across many disciplines. The framework identifies the sources of agility, a classification of agile activities, and the resources utilized by such activities.
\end{abstract}

\section{THE PROBLEM}

The work described in this paper was motivated initially by a concern regarding the lack of integrated and cohesive definitions of agile methods in information systems development ${ }^{\prime}$ (ISD). The formation of the Agile Alliance in 2001 and the publication

'The terms information system development and software development are used interchangeably for the purposes of this paper. 
of the Agile Manifesto (Fowler and Highsmith 2001) formally introduced agility to the field of ISD. Those involved sought to "restore credibility to the word method" (Fowler and Highsmith 2001). The Agile Manifesto presented an industry-led vision for a profound shift in the ISD paradigm through 12 principles. The Manifesto and its principles represent quite pioneering work in coalescing and extending the critique of formalized ISD methods over the past decade or so (Baskerville et al. 1992; Fitzgerald 1994, 1996) and have been well received by practitioners and academics.

However, there are a number of critical issues in the field, all of which revolve around a lack of rigor and cohesion.

- Many different definitions of an agile method exist. Researchers often use the same term to refer to different concepts and different terms to refer to the same concept. However, this is not surprising given that IS researchers cannot even reach consensus on the definitions of the most basic terms such as information system, method, and technique. In fact, Sharafi and Zhang (1999), Towill and Christopher (2002), and Vokurka and Fliedner (1998) have explicitly illustrated this issue in the case of the term agility.

- Many different agile methods exist, such as eXtreme Programming (XP) (Beck 1999), dynamic systems development method (DSDM) (Stapleton 1997); SCRUM (Schwaber and Beedle 2002); Crystal (Cockburn 2002b); agile modeling (Ambler 2002); feature driven design (Coad et al. 1999); lean programming (Poppendieck 2001), and perhaps even the rational unified process (RUP) (Kruchten 2000), all categorized as agile by those that use them. Each of these methods focuses heavily on some of the principles of the agile manifesto and ignore others completely, but yet are portrayed by some not only as an agile method, but as the best agile method.

- Some studies have advocated an a la carte approach such as "XP Lite," where an existing agile method is "defanged" (Stephens and Rosenberg 2003) and a subset method used. Others state that "the whole is better than the sum of its parts" and that agile methods are only beneficial when used in their entirety. However, even one of the main supporters of this notion has admitted that the system metaphor concept in XP is rarely, if ever, used (Fowler 2001), a sentiment felt by others in the field (Khaled et al. 2004; Succi and Marchesi 2001). Thus, one could argue that, strictly speaking, any team using XP in this way is not truly agile.

- At the other end of the spectrum, there are some, especially those using more traditional ISD methods, who disregard agile methods, as unstructured, ad hoc, glorified hacking.

- Cockburn (2002a) even dismisses the existence of an agile method altogether, claiming that it is something to which developers can only aspire, and that only hindsight can determine whether an agile method was actually adhered to.

- Finally, there is a perception among the purveyors of the agile method that all prior methods were non-agile. Given that changing requirements were a problem 
identified over a quarter of a century ago (Boehm et al. 1984), and that methods such as rapid application development were developed to handle such change, it is obvious that some parts of these dated methods at least contributed to agility. "Elements of agility can certainly be found in many processes, but as the saying goes-one swallow does not a make summer" (Alleman 2002, p. 54).

One reason for such a lack of consensus in the literature is that the principles of agility expressed in the Agile Manifesto (Fowler and Highsmith 2001) and the various agile methods in existence lack sufficient grounding in management theory, organizational theory, and indeed theory behind all the fields and disciplines which comprise ISD. Consequently, the Manifesto does not consider the evolution of the concept of agility in fields outside ISD. Agility is not a concept unique to software development. Indeed it first appeared in the mainstream business literature in 1991, when a group of researchers at the lacocca Institute of Lehigh University introduced the term "agile manufacturing" (Goldman et al. 1991). The industry-based report aimed to provide the United States with a weapon to regain its pre-eminence in manufacturing, and described the emerging agile principles being adopted by U.S., European, and Japanese firms as being the way forward. Since then, manufacturing companies across many industries have gained a competitive advantage from such an agile philosophy (Burgess 1994).

However, a review of the agile manufacturing literature indicates that even now, those who study agile manufacturing are having the same problems as those studying agile methods in ISD. There are many diverse and often contradicting definitions of agile manufacturing; the concepts lack a theoretical grounding, and consideration is not given to the differences between overall industry sectors and individual organizations (Burgess 1994).

This suggests that the search for a definitive, all-encompassing concept of agility may not be completed simply through an examination of agility in other fields. Rather the answer it is to be found through an examination of the underlying concepts of agility, namely flexibility and leanness (Sharafi and Zhang 1999; Towill and Christopher 2002) which have much older origins. For example, lean thinking can be traced back to the Toyota Production System in the 1950s with its focus on the reduction and elimination of waste (Ohno 1988), the production of the Spitfire airplane in World War II (Childerhouse et al. 2000), and even as far back as the automotive industry in 1915 (Drucker 1995).

\section{RESEARCH APPROACH}

In summary, the research approach undertaken and completed thus far is as follows:

- An extensive literature review was carried out to understand the historical evolution and maturation of the ISD field.

- An extensive literature review of agility was undertaken across a number of disciplines such as manufacturing, finance, and organizational behavior. Again, the objective of this review was to gain a better understanding of the historical evolution and maturation of the agile concept. 
- The output from the first two stages was used to produce an initial rough draft definition and taxonomy of agility, including headings and subheadings. Criteria for the taxonomy as a whole were that it should aim to be (1) of practical use and practice-connected, (2) inclusive but at the same time parsimonious in its topics and subtopics, (3) of minimal overlap, and (4) reasonably robust in accommodating developments in the field.

\section{FOR AND AGAINST A FRAMEWORK FOR THE FIELD}

The fields of IS and ISD have always drawn upon many others, such as computer science, organizational theory, linguistics, political science and psychology (Adam and Fitzgerald 1996; Ahituv and Neumann 1990; Avison 1996; Bariff and Ginzberg 1982; Culnan and Swanson 1986; Hirschheim et al. 1994; Vogel and Wetherbe 1984).

It has also been argued that the field cannot be disciplined or controlled by any imposed structure or paradigm, as in the Kuhnian model of scientific advancement, because of its technologically dynamic nature (Banville and Landry 1989). The emergence of agile methods such as XP and the tools such as automated acceptance testing associated with these methods are examples of such dynamism.

A third argument against a common ground, framework, or theory is that a monistic, single view would be restrictive, given the disparate backgrounds and pluralistic interests of those involved in the field (Banville and Landry 1989).

In contrast to the arguments against, there have been many arguments in favor of some unifying framework. For example, it has been argued that without such a framework or underlying theory, a field may be driven by technology or the events of the day (Weber 1987). It has also been said that a framework is needed so that researchers can build upon the development of a consistent set of data, and avoid reinventing the wheel (Grimshaw 1992). In addition, there is historical evidence of certain fields achieving progress at the expense of others through the establishment of a core, theoretical structure (Latour 1988).

A further argument in favor of some kind of framework and structure for a field is that, without it, "progress is but a fortunate combination of circumstances, research is fumbling in the dark, and the dissemination of knowledge is a cumbersome process" (Vatter 1947 p. 31). For example, it has been shown how the production of scientific fact is characterized as a process of creating cognitive order, or some sort of framework, out of disorder (Latour and Woolgar 1979).

\section{THE PROPOSED TIERED FRAMEWORK OF ISD AGILITY}

In previous research, we have reviewed the literature on agility across nany disciplines (Conboy and Fitzgerald 2004a; Conboy and Fitzgerald 2004b; Conboy and Fitzgerald $2004 \mathrm{c}$ ), and have arrived at the following over-arching, generic definition of agility: 
Agility is the continual readiness of an entity to rapidly or inherently, proactively or reactively, embrace change, through high quality, simplistic, economical components and relationships with its environment.

It is beyond the scope of this paper to illustrate the detailed derivation of this definition. However, we believe that it provides a rich enough basis to accommodate even very complex method instances where "just enough method" requires quite a comprehensive and detailed, formalized approach. We discuss and justify the phraseology of this definition next.

\subsection{Sources of Change}

The definition of agility proposed above places the concept of change at its core. In ISD, the emergence of agile methods has been put down to the need to handle change (Cockburn 2002a; Fowler 2000; Fowler and Highsmith 2001). However, there is a tendency in the field of ISD to over-concentrate on system requirements as the overwhelming source of change. The rationale behind agile methods such as XP and SCRUM is their ability to handle requirement changes, and not necessarily all of the changes that an ISD team may have to face. Therefore, the first part of the framework identifies a more comprehensive set of potential sources of change.

- Customers: Changing customer requirements was the driving force behind most of the methods proposed since the systems development life cycle. However, customers can be the source of other types of change. For example, a customer may change meeting times with developers, may insist on different deliverables, or may change budget allocations.

- Technology: This can refer to the impact a change in hardware and underlying software can have on the principal ISD project. An example would be a necessity to upgrade from Windows 2000 to Windows XP midway through development However, technology also refers to the methods and processes carried out during development (Schwalbe 2000; Shenhar and Dvir 1995). Furthermore, the probability of change arising as a result of using a method depends on the "newness of that method" (Williams 2002) and any inherent properties it possesses to remove discrepancies between public and private rationality, i.e., varying interpretations of the method and what it entails (Stolterman and Russo 1997).

- Social Factors: This is an umbrella term that includes cultural, political, and other similar issues that may drive change in an ISD project. For example, Schein (1965) discusses the concept of the complex man, his motives and abilities. He has many needs, arranged in a hierarchy of personal importance, but the hierarchy varies over time. This may change in accordance with different project environments, teams, methods and customers. Furthermore, a person's work involvement may also change in response to a change in these motives. For example, a highly skilled, poorly motivated worker may be as effective and satisfied as an unskilled but highly motivated worker. The implication for project managers is not that there is a single 


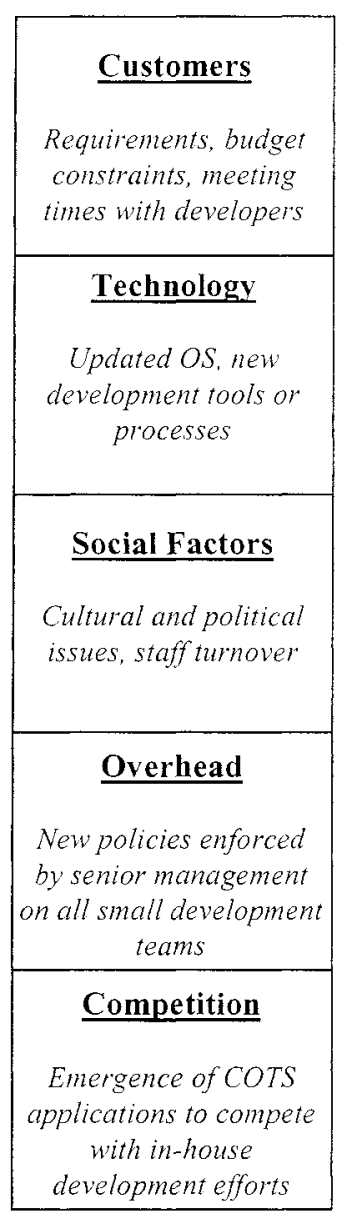

Figure 1. Sources of Change

method or strategy to adopt, but that the method must cater for and be adaptable to a variety of abilities and motives which may emerge during the course of a project (Carnall 2002).

- Overhead: This refers to any changes imposed by management over and above the ISD team. An example would be that a team within an international consulting organization would be forced to abide by new policies.

- Competition: This includes any changes imposed by the need to keep up with competitors and competitor or substitute products (Sharafi and Zhang 1999). 
A team should analyze these sources of change and identify which are applicable to them and which are not. Some will always be a source of change, such as customer requirements. However, some depend on the context of the project. For example, a team within a multinational consulting organization will incvitably be subjected to overhead change, whereas an independent team of Web developers may not.

\subsection{Classification of Agile Activities}

Once an ISD team has identified the potential sources of change it faces, it can conduct an analysis of the ability of its current or future activities to handle such change. However, the literature on agility and its subclassifications is complex and often inconsistent. There tends to be a lot of overlap between the concepts of agility, flexibility, and leanness. At a conceptual level, the following broad classifications of agility have been extracted from the literature:

- Change Creation: Agility is not just the ability to adapt to change; it also refers to the ability of an entity to positively impact its environment by initiating such change itself (Gerwin 1993). This suggests that proactive steps may "not just anticipate change, but may create it" (Piore 1989). Adapt to implies that change is the driving force and the entity's actions are as a result of that force. Change creation refers to a two-way process where the entity not only reacts to change but can also influence it. In an ISD context, this refers to situations where the ISD team is the primary instigator of change, as opposed to a team that is usually passive and change originates from the customer or from levels higher in the organization.

- Pro-action: Golden and Powell (2000) discuss the contrast between proactive and reactive flexibility. This concept recognizes the fact that an entity is not helpless while waiting for change to occur and that steps can be taken in advance of change as well as in response to it. The simple example of periodic inspection and preventative maintenance of equipment is a proactive approach to combating machine failure, as opposed to repair and replacement of equipment after failure, which is a reactive one (Gerwin 1993). Proactive versus reactive strategies have also been described as offensive versus defensive strategies (Golden and Powell 2000) and initiative versus response (Goldman et al. 1995). In an ISD context, this is where the ISD team takes actions to elicit changes before they actually occur. Prototyping is a prime example of this. Delaying decisions and staging the investment of resources are also examples of pro-action.

- Reaction: Reaction is the most commonly used interpretation of agility, defined as the ability to adapt to change. Even within this relatively simple component of agility, there exist different notions as to what it represents. For example the distinction between defensive and offensive strategies raises the issue that, after change occurs, not only can an entity attempt to return to its original state, but it can take advantage of the change to place itself in a better position (Golden and Powell 2000). Adapt to implies that an entity is homeostatic, and that its only objective in the face of change will be to return to its original state. Embrace implies that the 
entity may not only try to return to its original state but may capitalize on the change and improve on its position, hence the use of the term in the earlier definition. Reaction in an ISD context refers to the actions taken by the ISD team in response to a change.

- Learning: Although a lot of the earlier concepts such as pro-action and reaction indicated a large overlap between flexibility and agility, the concept of learning seems to make a distinction between them. Agility assumes that change is continuous, and embracing it is an ongoing activity. Furthermore, an agile entity should learn how to be more creative, proactive, and reactive over time. This assumption was laid down in the key contribution of Goldman et al. (1995), who described agility in general terms as "a continual readiness to change." The flexibility literature makes no reference to continual change as opposed to a onceoff change. Learning in an ISD context is where the project team learns from the change process so as to be more creative, proactive, and reactive during the next cycle.

One component often discussed in the literature on agility, but that does not form part of this proposed framework, is robustness. Hashimoto (1980; see also (Hashimoto et al. 1982) refers to robustness or resilience as a component of flexibility and agility. Robustness or resilience is the ability to endure all transitions caused by foreseen or unforeseen changes, or the degree of change tolerated before deterioration in performance occurs without any corrective action (Hashimoto 1980; Hashimoto et al. 1982). This concept indicates that in order to be truly flexible, an entity must not only be able to adapt to change by taking steps, but must also be able to embrace change by taking none. However, this framework does not include robustness as a component of agility. We believe this is justifiable since robustness is not an activity in itself but is a product of pro-action. In other words, proactive activities, if done well, should reduce the need to react. The less reaction required, the higher the level of robustness.

Activities can be analyzed under each of the four classifications of agility outlined above to see how they can contribute to the overall agility of the ISD team. These classifications can be combined with the sources of change identified in section 4.1 to allow a more thorough analysis of activities (see Figure 2)

The framework is not populated as the contents will depend on the specific ISD project and the reason for using the framework. Creative, proactive, reactive, and learning activities can only be aligned with the various sources of change once the project manager has identified the relevant sources of change and subcategories of change applicable to the specific project.

\subsection{Resource Utilization}

Leanness has been defined as the elimination of waste (Naylor et al. 1999; Ohno 1988; Womack et al. 1990) and doing more with less (Towill and Christopher 2002). Different authors have conflicting opinions regarding the benefits and drawbacks of using a lean approach. However, there is a general consensus that such an approach 


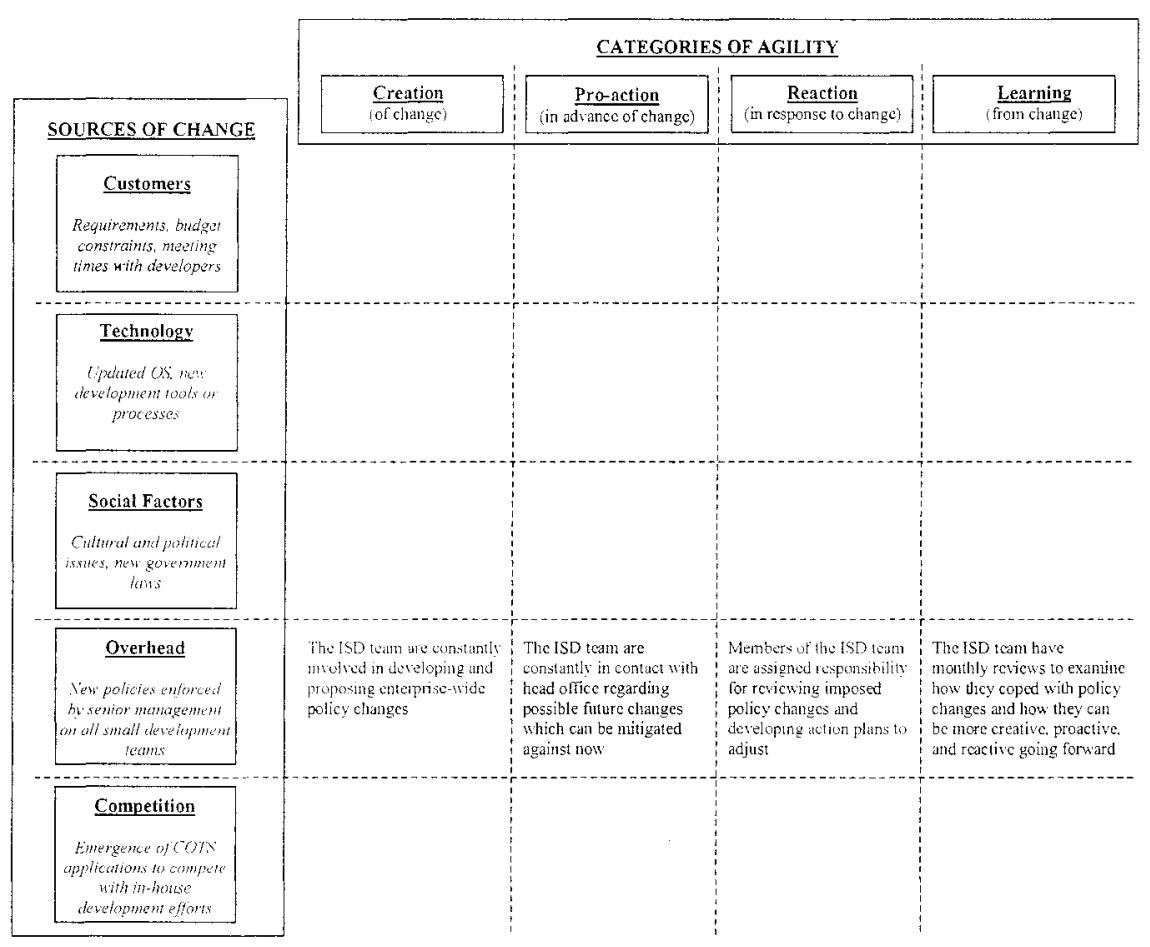

Figure 2. Classification of Agile Activities

advocates the utilization of all resources and no unnecessary resources are maintained (Naylor et al. 1999; Ohno 1988; Towill and Christopher 2002; Womack et al. 1990). Some believe that although agility exhibits similar traits to leanness in terms of simplicity and quality, the literature has identified one major difference in terms of economy (Young et al. 2001). Ultimate leanness is to eliminate all waste. Agility requires waste to be eliminated, but only to the extent where its ability to respond to change is not hindered. This does not remove the need to be economical, only lower its priority.

Identifying and handling change, or in other words being agile, requires resources. The development team faces the task of dealing with change while minimizing the cost, time, and diminished quality required to do so. Figure 3 represents this notion. The $x-$ axis measures the parameterized number of changes identified and fulfilled, the parameter depending on the source of change (refer to Figure 1). For example, the $x$ axis could be measured by the number of requirement changes, the staff turn-over count, or the number of policy changes introduced. The resources required to fuel the identification and handling of these changes, namely cost, time, and defects, are represented by the $y$-axis.

This part of the framework dispels the notion that an activity can be labeled as completely agile or non-agile. It depends on the context in which it is used. For example, prototyping is a proactive approach to eliciting customer requirements. The 


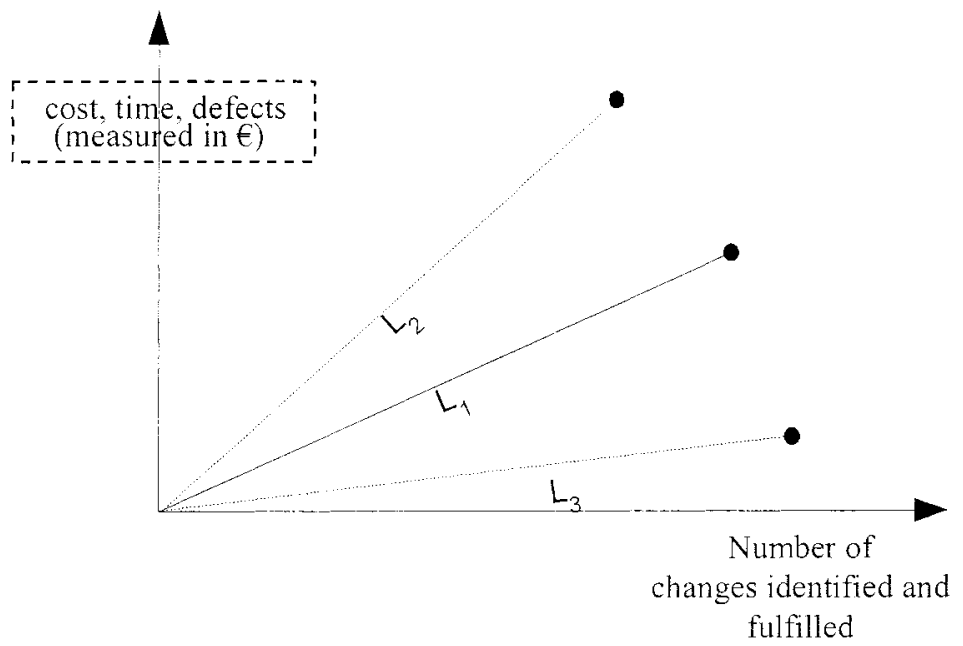

Figure 3. Resource Utilization

cost of developing a prototype and the amount of time taken to run a prototyping session must be weighed against the number of requirements usually elicited by such sessions. Given the law of diminishing returns, running too many sessions will be very costly, but the average number of requirements elicited per session will fall. Therefore, conducting prototyping sessions only contributes to agility if done in moderation. In Figure 3, if too many prototyping sessions are run, the line will rise from $L_{1}$ to $L_{2}$. The ideal target is to move the line closer to $L_{3}$ where there are a large number of requirements identified and handled for the relatively small amount of resources used

A limitation of this part of the framework is the subjective nature of some of the metrics used. Furthermore, it is difficult to estimate the resources utilized by an ISD activity before it takes place and impossible to predict the number of new changes identified as a result. Only in hindsight can the resources utilized be justified by the number of changes elicited and handled. This indicates that there is some element of truth in Highsmith's (1999) notion that only hindsight can determine whether an agile method was actually adhered to.

\section{IMPLICATIONS OF THE FRAMEWORK}

\subsection{In Practice}

It is expected that the framework can be used to remove a lot of the inconsistencies in the interpretation and use of agile methods. For example, a developer who believes that agile is a purely reactive capability can see where his/her ideas fit with other, more comprehensive interpretations. 
Also, the framework can be used to compare and contrast agile methods with each other, or even with more traditional approaches to determine their true agile content. An ISD team may not necessarily pick the method that ticks the most boxes in the matrix (Figure 2) but may pick the method that best handles the select sources of change that their project may face. Logically, therefore, it can also be used to identify gaps where they have identified sources of change to which they are prone but against which they are not protected.

The various components of agile methods can be individually analyzed, using the framework as a lens. For example, pair programming is proactive in terms of staff turnover in that it provides overlapping skills between developers should one decide to leave. It is also reactive with regard to errors, where two pairs of eyes are better than one at finding and resolving such bugs (Auer and Miller 2002). Such an individual analysis is useful to ISD teams who wish to adopt an a la carte approach to agile methods.

The framework can also be used for training purposes. The team can be made aware of the metrics that are important in terms of agility, such as cost and time reduction and defect prevention.

Finally, the framework can be used retrospectively to determine the agility of an ISD team in hindsight. This is in the same vein of thought as Highsmith's claim that only hindsight can determine whether an agile method was actually adhered to. An analysis can be done to ensure that the correct sources of change were anticipated and that the activities carried out to handle that change had the desired effect.

\subsection{In Research and Education}

First, the framework is at a relatively higher level of abstraction than most other frameworks of agility, both within ISD literature and outside it. As a result, this framework may provide a foundation to connect other pieces of work which adopt a narrower interpretation of agility. For example, it may allow a researcher who has only focused on the reactive aspect of agility to extend his/her work to the other components such as creation, pro-action, and learning. A big picture view tends to invite the insertion of those pieces that may be missing, or the extra detail that might be needed for a particular purpose or group.

Second, to the extent that a big-picture dialogue is facilitated, it may point to areas of uncertainty and areas where there is a need to know more. For example, a Ph.D. student might use the framework as a top-level roadmap in searching for areas of concern.

Third, this framework is based on literature from many disciplines. This may provide support to researchers who wish to extend this further through divergent research, which draws upon scholarship among different disciplines to address realworld needs (Brown 1992). It may encourage linking with and thinking about other related areas. It facilitates convergent research, developing clearly defined, specific lines of enquiry to validate promising hypotheses. Thus, where divergent research aims to incorporate the big-picture view, the framework may be of value.

By synthesizing the literature and concepts of agility into sources of change, agile classifications, and resource utilization, there may be an opportunity to increase awareness of how important all three are to the overall agility of an enterprise. 
Finally, this framework may be applicable outside of the field of ISD to areas such as manufacturing where the same problems regarding inconsistency persist.

\section{FUTURE WORK}

The next stage of this research is a Delphic survey of leading academics and practitioners in the field of ISD, with a view to testing the three parts of the framework. This will be done by circulating this paper to the aforementioned individuals, and inviting their feedback. The framework will then be revised, based on the feedback from this survey.

Also, once this framework has been refined after practitioner and academic feedback, the next step will be to refine and elaborate the framework. For example, the sources of change may be broken down into a more comprehensive and detailed list of ISD-specific components.

\section{REFERENCES}

Adam, F., and Fitzgerald, B. "A Framework for Analyzing the Evolution of the IS Field: Can IS Become a Stable Discipline," in Proceedings of the $4^{\text {th }}$ European Conference on Information Systems, Lisbon, June 1996, pp. 17-32.

Ahituv, N., and Neumann, S. Principles of Information Systems for Management, Dubuque, IA: Brown, 1990.

Alleman, G. "Agile Project Management Methods for IT Projects," in The Story of Managing Projects: A Global, Cross-Disciplinary Collection of Perspectives, E. Carayannis and Y. Kwak (Eds.), Berkeley, CA: Greenwood Press, 2002.

Ambler, S. W. Agile Modeling: Best Practices for the Unified Process and Extreme Programming, New York: John Wiley \& Sons, 2002.

Auer, K., and Miller, R. Extreme Programming Applied: Playing to Win, Upper Saddle River, NJ: Addison-Wesley, 2002.

Avison, D. "The Discipline of Information Systems: IS Teaching, Research and Practice," UK Academy of Information Systems, Cranfield University, 1996.

Banville, C., and Landry, M. "Can the Field of MIS be Disciplined?," Communication of the ACM (32:1), 1989, pp. 48-60.

Bariff, M., and Ginzberg, M. "MIS and the Behavioral Sciences: Research Patterns and Prescriptions," DATA BASE for Advances in Information Systems (14:1), 1982, pp. 19-26.

Baskerville, R., Travis, J., and Truex, D. "Systems Without Method: The Impact of New Technologies on Information Systems Development Projects," in The Impact of Computer Supported Technologies on Information Systems Development, K. Kendall, K. Lyytinen, and J. I. DeGross (Eds.), Amsterdam: Elsevier Science Publishers, 1992, pp. 241-269.

Beck, K. Extreme Programming Explained, Upper Saddle River, NJ: Addison Wesley, 1999.

Boehm, B., Gray, T., and Seewaldt, T., "Prototyping Versus Specifying: A Multi-Project Experiment," IEEE Transactions on Software Engineering (SE-10:3), 1984, pp. 290-302.

Brown, R. "The State of the Art of Decision Analysis: A Personal Perspective," Interfaces (22:6), 1992, pp. 5-14.

Burgess, T. "Making the Leap to Agility: Defining and Achieving Agile Manufacturing through Business Process Redesign and Business Network Redesign," International Journal of Operations and Production Management (14:11), 1994, pp. 23-34. 
Carnall, C. Managing Change in Organizations, Harlow, England: Prentice Hall, 2002.

Childerhouse, P., Disney, S., and Towill, D. "Speeding Up the Progress Curve Towards Effective Supply Chain Management," International Joumal of Supply Chain Management (5:3), 2000, pp. 176-186.

Coad, P., de Luca, J., and Lefebre, E. Java Modeling in Color, Upper Saddle River, NJ; Prentice Hall, 1999.

Cockburn. A. Agile Software Development, Upper Saddle River, NJ: Addison Wesley, 2002a.

Cockburn, A. "Agile Software Development Joins the 'Would-Be' Crowd," Cutter IT Joumal (15:1), 2002b, pp. 6-12.

Conboy, K., and Fitzgerald, B. "A Multi-Disciplinary Literature Review of Agility," paper presented at the Americas Conference on Information Systems, New York, August 6-8, $2004 a$.

Conboy, K., and Fitzgerald, B. "The Resources Required to Fuel the Agile Fire," paper presented at the Multidisciplinary Software Engineering Conference, Los Angeles, August 21-25, 2004b.

Conboy, K., and Fitzgerald, B. "Towards a Conceptual Framework of Agile Methods," paper presented at the XP and Agile Conference, Alberta, Canada, August 15-18, 2004c.

Culnan, M., and Swanson, E. "Research in MIS 1980-1984: Points of Work and Reference," MIS Quarterly (10:3), September 1986, pp. 289-301.

Drucker, P. "The Information That Executives Truly Need," Harvard Business Review, JanuaryFebruary 1995, pp. 54-62.

Fitzgerald, B. "Formalized Systems Development Methodologies: A Critical Perspective." Information Systems Journal (6:1), 1996, pp. 3-23.

Fitzgerald, B. "The Systems Development Dilemma: Whether to Adopt Formalized Systems Development Methodologies or Not," in Proceedings of the Second European Conference on Information Systems, W. Baets (Ed.), Nijenrode, Holland: Nijenrode University Press, 1994, pp. 691-706.

Fowler, M. "Is Design Dead," Chapter 1 in Extreme Programming Explained, Upper Saddle River, NJ: Addison-Wesley, 2001.

Fowler, M. "Put Your Process on a Diet," Software Development, December 2000, pp. 32-36.

Fowler, M., and Highsmith, J. "The Agile Manifesto,"Software Development, August 2001, pp. 17-25.

Gerwin, D. "Manufacturing Flexibility: A Strategic Perspective," Management Science (39:4), 1993, pp. 395-410.

Golden, W., and Powell, P. "Towards a Definition of Flexibility: In Search of the Holy Grail?," Omega (28), 2000, pp. 373-384.

Goldman, S., Nagel, R., and Preiss, K. Agile Competitors and Virtual Organizations: Strategies for Enriching the Customer, New York: Von Nostrand Reinhold, 1995

Goldman, S., Nagel, R., Preiss, K., and Dove, R. Iacocca Institute: $21^{\text {st }}$ Century Manufacturing Enterprise Strategy: An Industry Led View, Bethlehem, PA: Iacocca Institute, Lehigh University, 1991.

Grimshaw, D. "Towards a Taxonomy of Information Systems: Or Does Anyone Need a TAXI," Journal of Information Technology (7:1), 1992, pp. 30-36.

Hashimoto, T. "Robustness, Reliability, Resilience and Vulnerability Criteria for Planning," Water Resources Research (8:1), 1980, pp. 11-47.

Hashimoto, T., Loucks, D., and Stedinger, J. "Robustness of Water Resources Systems," Water Resources Research (18:1), 1982, pp. 21-26.

Highsmith, J. Adaptive Software Development, New York: Dorset House, 1999.

Hirschheim, R., Klein, H., and Lyytinen, K. "Exploring the Intellectual Structures of IS Development: A Social Action Theoretic Analysis," Accounting, Management and Information Technology (6:1), 1994, pp. 1-64. 
Khaled, R. Barr. P., and Biddle, B. "System Metaphor in 'Extreme Programming": A Semiotic Approach," in Proceedings of the International Workshop on Organizationa Semiotics. Setubal, Portugal: INSTICC Press, August 2004, pp. 152-172.

Kruchten, P. The Rational Unified Process: An Introduction, Reading, MA: Addison-WesleyLongman, 2000.

Latour, B. The Pasteurisation of France, Boston: Harvard University Press, 1988.

Latour. B.. and Woolgar, S. Laboratory Life, London: Sage Publications, 1979.

Naylor. J., Naim, M., and Berry, D. "Leagility: Integrating the Lean and Agile Manufacturing Paradigm in the Total Supply Chain," Engineering Costs and Production Economics (62). 1999, pp. 107-118.

Ohno, T. The Toyota Production System: Beyond Large Scale Production, Portland, OR: Productivity Press, 1988.

Piore, M. "Corporate Reform in American Manufacturing and the Challenge to Economic Reform," Mimeo, Department of Political Science, Massachusetts Institute of Technology. 1989.

Poppendieck, M. "Lean Programming," Software Development Magazine (9:5), 2001, 71-75.

Schein, E. Organizational Psychology, Englewood Cliffs, NJ: Prentice Hall, 1965.

Schwaber, K., and Beedle, M. Agile Software Development with Scrum, Upper Saddle River, NJ: Prentice Hall, 2002.

Schwalbe, K. Information Technology Project Management, Boston: Course Technology, 2000.

Sharafi. H., and Zhang, Z. "A Method for Achieving Agility in Manufacturing Organizations: An Introduction," International Journal of Production Economics (62:1-2), 1999, pp. 7-22.

Shenhar, A., and Dvir, D. "Managing Technology Projects: A Contingent Exploratory Approach," in Proceedings of the $28^{\text {th }}$ Annual Hawail International Conference on System Sciences, Los Alamitos, CA: IEEE Computer Society Press, 1995, pp. 494-503.

Stapleton, J. DSDM: Dynamic Systems Development Method, Harlow, England: Addison Wesley, 1997.

Stephens, M., and Rosenberg, D. Extreme Programming Refactored, Berkeley, CA: Apress, 2003.

Stolterman, E., and Russo, N. "The Paradox of Information Systems Methods: Public and Private Rationality," paper presented at the British Computer Society Annual Conference on IS Methodologies, August 27-29, 1997.

Succi, G., and Marchesi, M. Extreme Programming Examined, Reading, MA: Addison-Wesley Longman, 2001.

Towill, D., and Christopher, M. "The Supply Chain Strategy Conundrum: To Be Lean or Agile or To Be Lean and Agile," International Journal of Logistics: Research and Applications (5:3), 2002, pp. 4-11.

Vatter, W. The Fund Theory of Accounting and its Implications for Financial Reports, Chicago: The University of Chicago Press, 1947.

Vogel, D., and Wetherbe, J. "MIS Research: A Profile of Leading Journals and Universities." DATA BASE for Advances in Information Systems (16:1), 1984, pp. 3-14.

Vokurka, R., and Fliedner, G. "The Journal Toward Agility," Journal of Industrial Management and Data Systems (98:4), 1998, pp. 165-171.

Weber, R. "Towards a Theory of Artifacts: A Paradigmatic Base for Information Systems Research," Journal of Information Systems (1:2), 1987, pp. 3-19.

Williams, T. Modeling Complex Projects, New York: Wiley and Sons, 2002.

Womack, J., Jones, D., and Roos, D. The Machine That Changed the World, New York: Rawson Associates, 1990.

Young, K., Muehlhaeusser, R., Piggin, R., and Rachitrangsan, P. "Agile Control Systems," Automobile Engineering (215:D2), 2001, pp. 189-195. 


\begin{abstract}
ABOUT THE AUTHORS
Kieran Conboy is a junior lecturer in Information Systems at the National University of Ireland, Galway, Ireland. His current doctoral research focuses on agile methods for systems development as well as agility across other disciplines. Prior to joining NUI Galway, he was a management consultant with Accenture. Kieran can be reached at kieran.conboy@nuigalway.ie.

Brian Fitzgerald holds the Frederick A Krehbiel II Chair in Innovation in Global Business and Technology at the University of Limerick, Ireland, where he also is a Research Fellow of the University, in addition to being a Science Foundation Ireland Investigator. He has a Ph.D. from the University of London and has held positions at University College Cork, Ireland, Northern Illinois University, United States, the University of Gothenburg, Sweden, and Northumbria University, United Kingdom. His publications include seven books and more than 70 papers, published in leading international conferences and journals. Having worked in industry prior to taking up an academic position, he has more than 20 years experience in the IS field. Brian can be reached atbf@ul.ie.

William Golden is a senior lecturer in Information Systems and a research director of the Centre for Innovation and Structural Change at the National University of Ireland, Galway, Ireland. His current research focuses on how such interorganizational networks enable innovative practices, which enable networked firms, to out perform their rivals. He has coauthored a book, contributed chapters to other texts, and published papers in the areas of electronic commerce and information systems in such journals as Omega, The International Journal of Management Science, International Journal of Electronic Commerce and Journal of End-User Computing. Willie can be reached at willie.golden@nuigalway.ie.
\end{abstract}

